\title{
Improvement of glucose intolerance by combination of pravastatin and olmesartan in type II diabetic KK-A' mice
}

Harumi Kanno, Masaru Iwai, Shinji Inaba, Izumi Senba, Hirotomo Nakaoka, Hisako Sone, Masaki Mogi and Masatsugu Horiuchi

The effects of the coadministration of pravastatin and an angiotensin type $1\left(\mathrm{AT}_{1}\right)$ receptor blocker, olmesartan, on glucose intolerance were examined using type II diabetic mice. Male KK-A ${ }^{y}$ mice ( 8 weeks of age) were treated with pravastatin and/or olmesartan for 2 weeks. An oral glucose tolerance test (OGTT) was performed with an administration of $2 \mathrm{~g} \mathrm{~kg}^{-1} \mathrm{glucose}^{\text {. Tissue }}$ glucose uptake was determined using $2-\left[{ }^{3} \mathrm{H}\right]$ deoxyglucose. The treatment of mice with pravastatin attenuated the increase in the plasma glucose level during OGTT in a dose-dependent manner, without affecting the plasma insulin level. Pravastatin increased glucose uptake in insulin-sensitive tissue such as the skeletal muscle and adipose tissue after treatment at $5-20 \mathrm{mg} \mathrm{kg}^{-1}$ day $^{-1}$ for 2 weeks, but not at $1 \mathrm{mg} \mathrm{kg}^{-1}$ day $^{-1}$. The combination of a noneffective dose of pravastatin $\left(1 \mathrm{mg} \mathrm{kg}^{-1}\right.$ day $\left.^{-1}\right)$ and a noneffective dose of olmesartan $\left(0.5 \mathrm{mg} \mathrm{kg}^{-1}\right.$ day $\left.^{-1}\right)$ synergistically improved OGTT without affecting the plasma insulin level. This combination also increased $2-\left[{ }^{3} \mathrm{H}\right]$ deoxyglucose uptake in the skeletal muscle and adipose tissue. The effects of pravastatin or olmesartan on OGTT and tissue 2-[3 $\mathrm{H}]$ deoxyglucose uptake were significantly enhanced by an antioxidant, tempol, whereas the effects of a pravastatin-olmesartan combination were not further enhanced by tempol. These results indicate that the combination of pravastatin and olmesartan synergistically improves glucose intolerance through an increase in tissue glucose uptake. The effects seem to be mediated by an increase in insulin sensitivity through the inhibition of oxidative stress.

Hypertension Research (2009) 32, 706-711; doi:10.1038/hr.2009.81; published online 29 May 2009

Keywords: angiotensin; glucose intolerance; oxidative stress; receptor; statin

\section{INTRODUCTION}

The renin-angiotensin system (RAS) has a critical role in cardiovascular function. Angiotensin (Ang) II is a major bioactive substance in RAS. Most actions of Ang II are mediated through angiotensin type 1 $\left(\mathrm{AT}_{1}\right)$ receptor stimulation. $\mathrm{AT}_{1}$ receptor blockers $(\mathrm{ARB})$ show beneficial effects on cardiovascular disorders, such as vascular remodeling, inflammation, cardiac remodeling after infarction and atherosclerosis. Previous reports indicate that RAS is also involved in insulin resistance and metabolic disorders. ${ }^{1-3}$ In our previous report, an ARB, valsartan, improved glucose intolerance in diabetes model mice by enhancing insulin sensitivity. ${ }^{4}$ Moreover, recent studies suggest that a coadministration of ARBs with other antihypertensive drugs shows beneficial effects on cardiovascular diseases. We recently reported that a calcium channel blocker, azelnidipine, synergistically enhanced the inhibitory action of an ARB, olmesartan, on brain ischemia. ${ }^{5}$

On the other hand, statins are widely used for patients with hypercholesterolemia and atherosclerosis. The beneficial effects of statins are induced by a reduction of cholesterol synthesis through an inhibition of HMG-CoA reductase. In addition, recent studies have reported pleiotropic effects of statins on oxidative stress, inflammation and endothelial dysfunction. ${ }^{6,7}$ Indeed, we have previously reported that a statin inhibited atherosclerotic lesion formation, lipid accumulation, inflammatory response as well as oxidative stress in apolipoprotein E-deficient mice. ${ }^{8}$ Moreover, a subeffective dose of statin enhanced the inhibitory effects of an ARB on atherosclerotic changes in these mice. ${ }^{8}$ In clinical studies, statins are suggested to improve cardiovascular events in diabetic patients. ${ }^{9,10}$ Such a beneficial action of statins may be more apparent in type II diabetic patients with hyperglycemia, hyperinsulinemia and hyperlipidemia. However, the effect of statins on glucose intolerance is still controversial. Moreover, the mechanism of action of a statin-ARB combination on glucose intolerance is not yet clear. In this study, we examined the effects of a combination of pravastatin and an $\mathrm{ARB}$, olmesartan, on glucose intolerance in type II diabetic KK-A mice, focusing on the involvement of oxidative stress. 


\section{METHODS}

Animals and treatment

Male KK- $\mathrm{A}^{\mathrm{y}}$ and C57BL/6J mice were obtained from Clea Japan Inc. (Tokyo, Japan), and housed individually from 8 weeks of age in plastic cages at $25 \pm 1^{\circ} \mathrm{C}$ with lights on from 0600 to 1800 hours. KK- $A^{y}$ mice result from a cross between glucose-intolerant black KK female mice and male yellow obese $\mathrm{A}^{\mathrm{y}}$ mice, and are known to serve as an excellent model of type II diabetes. ${ }^{11}$ They were given a standard diet (MF, Oriental Yeast Co. Ltd, Tokyo, Japan) and water ad libitum. KK- $\mathrm{A}^{\mathrm{y}}$ mice at 8 weeks of age were administered pravastain (CS514: 1, 5 and $20 \mathrm{mg} \mathrm{kg}^{-1} \mathrm{day}^{-1}$, donated by Daiich Sankyo Co. Ltd, Tokyo, Japan) orally for 2 weeks and/or olmesartan (RNH-6270; $0.5 \mathrm{mg} \mathrm{kg}^{-1} \mathrm{day}^{-1}$, donated by Daiich Sankyo Co. Ltd) for 2 weeks using an osmotic mini-pump implanted intraperitoneally. Tempol (2,2,6,6-tetramethyl-1-piperidinyloxy, radical; Wako Pure Chemical Industries Ltd, Tokyo, Japan) was administered in drinking water $\left(10 \mathrm{mmoll}^{-1}\right)$ for 2 weeks. Blood pressure was measured by the indirect tail-cuff method (MK-1030, Muromachi Kikai Co. Ltd, Tokyo, Japan). All experimental procedures were approved and carried out in compliance with the Guide for the Care and Use of Laboratory Animals as adopted and promulgated by the US National Institutes of Health and with the guidelines of the Ehime University Graduate School of Medicine Committee on Animals.

\section{Oral glucose tolerance test (OGTT)}

OGTT was performed after a 16-hour overnight fast. Glucose $\left(2 \mathrm{~g} \mathrm{~kg}^{-1}\right)$ was administered orally, and blood was collected from the orbital sinus at $0,30,60$ and $120 \mathrm{~min}$. Plasma glucose and plasma insulin were measured using commercial kits (Glucose CII test, Wako Pure Chemical Industries Ltd, Osaka, Japan; Insulin measurement kit, Morinaga Institute of Biological Science Inc., Yokohama, Japan, respectively).

\section{Measurement of rate constant of net tissue uptake of 2- $\left[{ }^{3} \mathrm{H}\right]$ deoxy-D-glucose}

The uptake of $2-\left[{ }^{3} \mathrm{H}\right]$ deoxy-D-glucose $\left(2-\left[{ }^{3} \mathrm{H}\right] \mathrm{DG}\right)$ in peripheral tissues was measured as previously reported. ${ }^{4}$ Skeletal muscles (extensor digitorum longus [EDL], soleus and red and white parts of gastrocnemius) were rapidly dissected and weighed. The rate constant of net tissue uptake of 2-[ $\left.{ }^{3} \mathrm{H}\right] \mathrm{DG}$ was calculated as described previously. ${ }^{12,13}$

\section{Statistical analysis}

All values are expressed as mean \pm s.e.m. The effects of the different treatments on all data were evaluated by factorial analysis of variance. When a significant effect was found, the results were further compared with Bonferroni's multiple range test. A difference with $P<0.05$ was considered significant.

\section{RESULTS}

Effects of pravastatin on OGTT in $\mathrm{KK}-\mathrm{A}^{\mathrm{y}}$ mice

As an animal model of type II diabetes, $\mathrm{KK}-\mathrm{A}^{\mathrm{y}}$ mice showed obesity, hyperglycemia and hyperinsulinemia. The administration of pravastatin, an HMG-CoA reductase inhibitor, at a dose of $20 \mathrm{mg} \mathrm{kg}^{-1} \mathrm{day}^{-1}$ for 2 weeks, but not at $5 \mathrm{mg} \mathrm{kg}^{-1} \mathrm{day}^{-1}$, significantly decreased the plasma cholesterol level (Table 1). Even at $20 \mathrm{mg} \mathrm{kg}^{-1} \mathrm{day}^{-1}$ of pravastatin, body weight and systolic blood pressure did not differ from those in control (Table 1).
As shown in Figure 1, pravastatin decreased the plasma glucose level in a dose-dependent manner in a fed state without restriction of feeding, whereas there was no significant difference in the plasma insulin level. Figure 2 shows the changes in plasma glucose and insulin in OGTT. The plasma glucose level at time 0 (that is, after fasting) was not different in each pravastatin group. However, the peak of plasma glucose at $30 \mathrm{~min}$ after glucose load was decreased by pravastatin at a dose of 5 and $20 \mathrm{mg} \mathrm{kg}^{-1}$ day $^{-1}$ without a significant difference in the plasma insulin level (Figure 2b). On the other hand, pravastatin at a dose of $1 \mathrm{mg} \mathrm{kg}^{-1}$ day $^{-1}$ did not change the plasma glucose curve in OGTT compared with that in non-treated mice (Figure 2a).
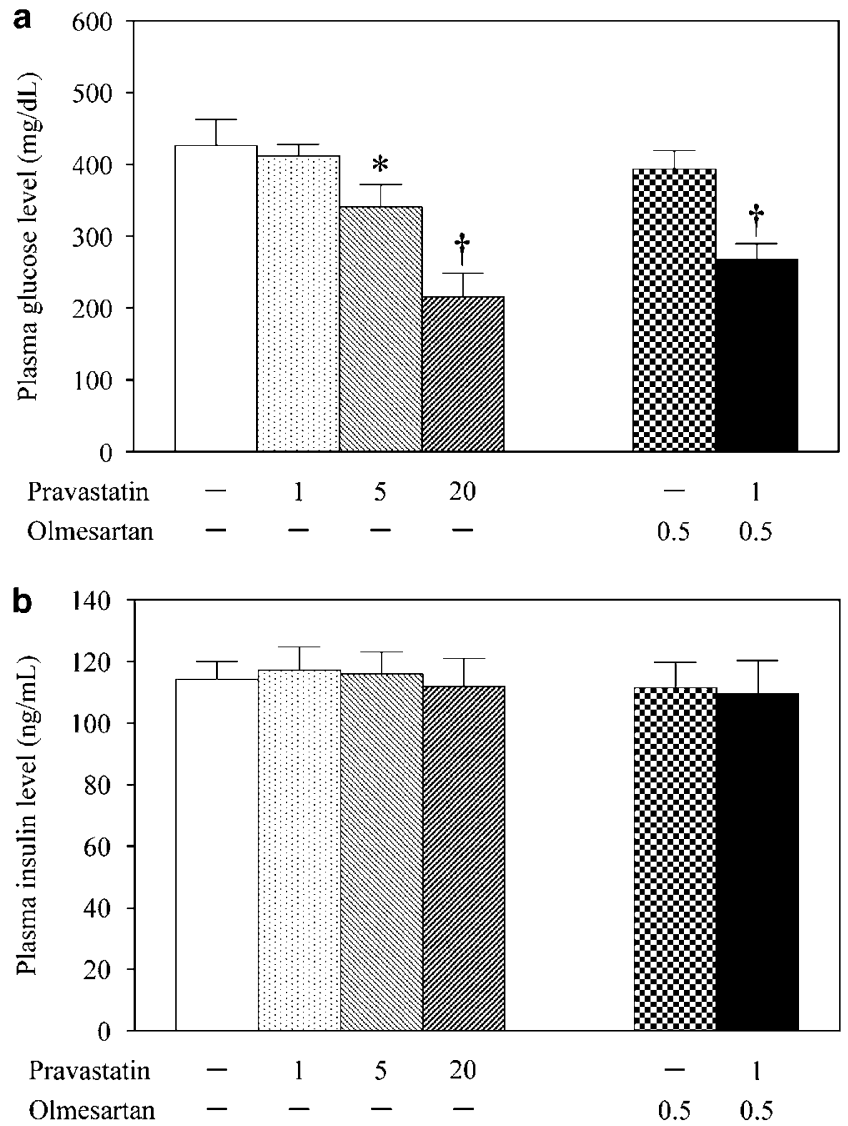

Figure 1 Plasma levels of glucose (a) and insulin (b) in fed condition in KK- $A^{\mathrm{y}}$ mice. Male KK-A $\mathrm{A}^{\mathrm{y}}$ mice were treated with pravastatin and/or olmesartan for 2 weeks, blood samples were obtained and plasma concentrations of glucose and insulin were determined as described in 'Methods'. Data are mean \pm s.e.m. from 6-8 animals for each group. Pravastatin: $\mathrm{mg} \mathrm{kg}^{-1}$ day $^{-1}$. Olmesartan: $\mathrm{mg} \mathrm{kg}^{-1} \mathrm{day}^{-1}{ }^{*} P<0.05,{ }^{\dagger} P<0.01$ vs. control.

Table 1 Body weight, blood pressure and plasma cholesterol level after treatment with pravastatin

\begin{tabular}{lcc}
\hline Treatment with pravastatin & Control & $5 \mathrm{mg} \mathrm{kg}^{-1}$ day $^{-1}$ \\
\hline Body weight (g) & $37.6 \pm 0.73$ & $37.3 \pm 0.42$ \\
Systolic blood pressure (mm Hg) & $123.7 \pm 2.4$ & $35.7 \pm 0.23$ \\
Plasma cholesterol (mg per $100 \mathrm{ml})$ & $184.6 \pm 4.5$ & $120.6 \pm 4.1$ \\
\hline
\end{tabular}

Pravastatin was administered for 2 weeks as described in 'Methods'. Data are mean \pm s.e.m. from $6-8$ animals for each group. ${ }^{*} P<0.05$ vs. control. 

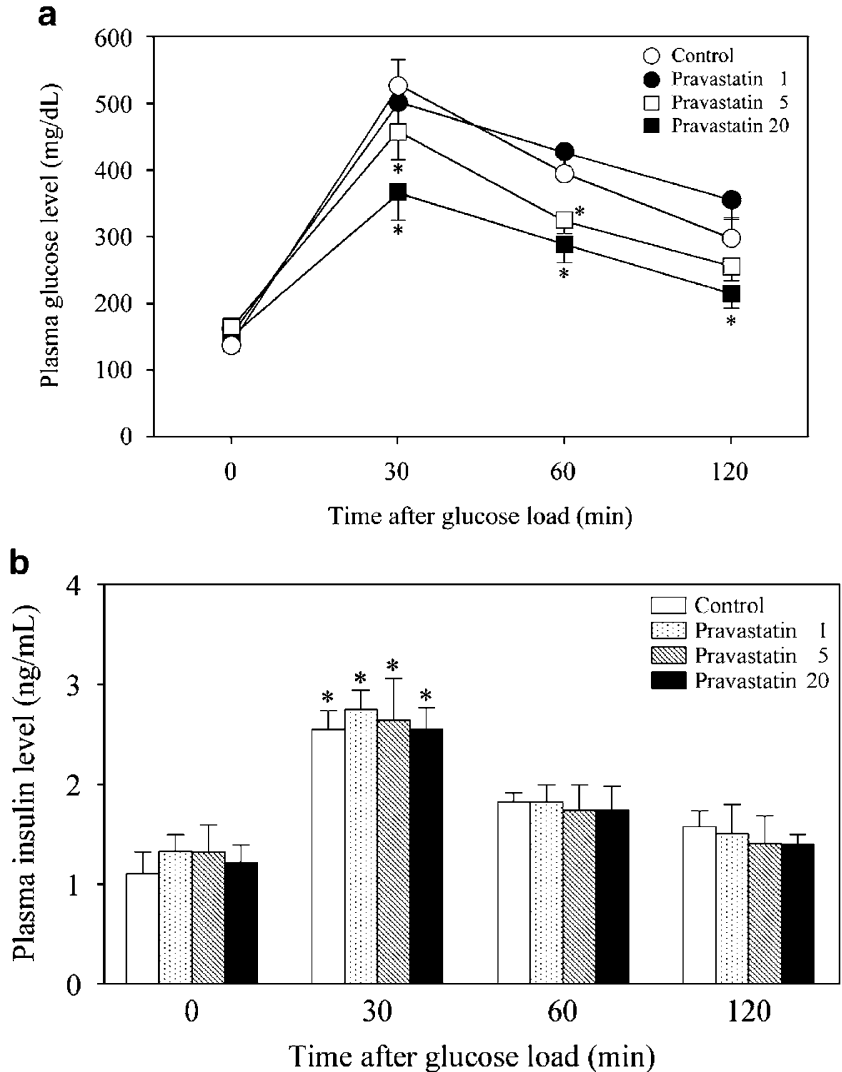

Figure 2 Effect of pravastatin in the oral glucose tolerance test (OGTT). KK$A^{y}$ mice were treated with pravastatin for 2 weeks at the doses indicated. OGTT was performed as described in 'Methods'. Changes in plasma glucose concentration (a) and insulin concentration (b) after a glucose load are shown. Data of the control group are indicated in each graph for comparison. Data are mean \pm s.e.m. from 4 to 5 animals for each group. Pravastatin: $\mathrm{mg} \mathrm{kg}^{-1} \mathrm{day}^{-1}$. ${ }^{*} P<0.05$ vs. control.

\section{Effects of coadministration of pravastatin and olmesartan on OGTT in $\mathrm{KK}-\mathrm{A}^{\mathrm{y}}$ mice}

A combination of noneffective doses of pravastatin $\left(1 \mathrm{mg} \mathrm{kg}^{-1} \mathrm{day}^{-1}\right)$ and olmesartan $\left(0.5 \mathrm{mg} \mathrm{kg}^{-1} \mathrm{day}^{-1}\right)$ decreased the plasma glucose level in a fed condition without a significant change in the plasma insulin level (Figure 1). This combination of pravastatin and olmesartan significantly decreased the peak value of the plasma glucose level in OGTT (Figure 3). Olmesartan alone did not change the plasma glucose or insulin level in a fed condition or in OGTT at this dose (Figures 1 and 3 ). In addition, we have already reported that olmesartan, even at a dose of $3 \mathrm{mg} \mathrm{kg}^{-1} \mathrm{day}^{-1}$, did not affect blood pressure in KK-A ${ }^{\mathrm{y}}$ mice. $^{14}$

\section{Effects of coadministration of pravastatin and olmesartan on glucose uptake in $\mathrm{KK}-\mathrm{A}^{\mathrm{y}}$ mice}

Next, we examined the effect of pravastatin on glucose uptake in insulin-sensitive tissues in KK-A $\mathrm{A}^{\mathrm{y}}$ mice using 2- $\left[{ }^{3} \mathrm{H}\right] \mathrm{DG}$. Pravastatin at a dose of $20 \mathrm{mg} \mathrm{kg}^{-1}$ day $^{-1}$ significantly increased the $2-\left[{ }^{3} \mathrm{H}\right] \mathrm{DG}$ uptake in skeletal muscle in the hindlimb and adipose tissue (Figure 4). However, neither pravastatin alone at $1 \mathrm{mg} \mathrm{kg}^{-1}$ day $^{-1}$ nor olmesartan alone at $0.5 \mathrm{mg} \mathrm{kg}^{-1} \mathrm{day}^{-1}$ affected the $2-\left[{ }^{3} \mathrm{H}\right] \mathrm{DG}$ uptake in these tissues, including in the skeletal muscle (Figure 5). A combination of noneffective doses of pravastatin $\left(1 \mathrm{mg} \mathrm{kg}^{-1} \mathrm{day}^{-1}\right)$ and olmesartan $\left(0.5 \mathrm{mg} \mathrm{kg}^{-1} \mathrm{day}^{-1}\right)$ increased the $2-\left[{ }^{3} \mathrm{H}\right] \mathrm{DG}$ uptake in skeletal muscle

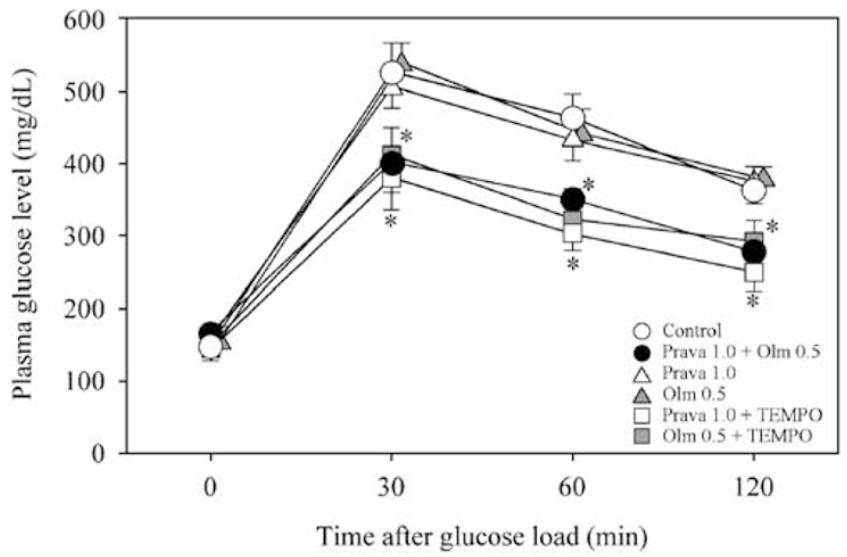

Figure 3 Effect of pravastatin and olmesartan in the oral glucose tolerance test (OGTT). KK-Ay mice were treated with pravastatin and olmesartan for 2 weeks at the doses indicated. OGTT was performed as described in 'Methods'. Data are mean \pm s.e.m. from 5-8 animals for each group. Prava: pravastatin ( $\mathrm{mg} \mathrm{kg}^{-1} \mathrm{day}^{-1}$ ), Olm: olmesartan $\left(\mathrm{mg} \mathrm{kg}^{-1} \mathrm{day}^{-1}\right.$ ). ${ }^{*} P<0.05$ vs. control.

and adipose tissue to a similar degree as that of pravastatin at a dose of $20 \mathrm{mg} \mathrm{kg}^{-1} \mathrm{day}^{-1}$ (Figure 5).

\section{Participation of oxidative stress in OGTT and glucose uptake} in $\mathrm{KK}-\mathrm{A}^{\mathrm{y}}$ mice with the antioxidant, tempol

To investigate the possible involvement of antioxidative actions in the effects of the pravastatin-omesartan combination to improve insulin sensitivity, mice were treated with an antioxidant, tempol $\left(10 \mathrm{mmol}^{-1}\right.$ in drinking water), for 2 weeks. In OGTT, tempol enhanced the effects of pravastatin or olmesartan at noneffective doses, resulting in an attenuation of the plasma glucose levels in OGTT (Figure 3). Moreover, tempol significantly enhanced the effect of a noneffective dose of pravastatin or olmesartan on $2-\left[{ }^{3} \mathrm{H}\right] \mathrm{DG}$ uptake in skeletal muscle and adipose tissue to a similar degree as that of a combination of noneffective doses of pravastatin and olmesartan (Figure 5). The administration of tempol alone did not significantly increase the 2- $\left[{ }^{3} \mathrm{H}\right] \mathrm{DG}$ uptake in skeletal muscle and adipose tissue (Figure 5). In addition, tempol tended to enhance the increase in $2-\left[{ }^{3} \mathrm{H}\right] \mathrm{DG}$ uptake caused by a combination of noneffective doses of pravastatin and olmesartan (Figure 5).

\section{DISCUSSION}

This study demonstrated that treatment of $\mathrm{KK}-\mathrm{A}^{\mathrm{y}}$ mice with pravastatin for 2 weeks decreased plasma glucose level and improved OGTT and increased glucose uptake in insulin-sensitive tissues, such as skeletal muscle and adipose tissue, in a dose-dependent manner. Moreover, we observed that glucose intolerance in type II diabetic KK-A $\mathrm{A}^{\mathrm{y}}$ mice was effectively improved by a combination of noneffective doses of pravastatin and olmesartan. This combination did not modify the plasma insulin level in both a fed condition and OGTT. Instead, the combination increased glucose uptake in skeletal muscle and adipose tissue.

Clinical studies suggest that treatment with ARB delayed the onset of diabetes. We have previously reported that an ARB, valsartan, improved glucose intolerance in type II diabetic KK-Ay mice. ${ }^{4}$ Another ARB, olmesartan, also improved OGTT and tissue glucose uptake and enhanced the effects of a CCB, azelnidipine, on glucose intolerance. ${ }^{14}$ 

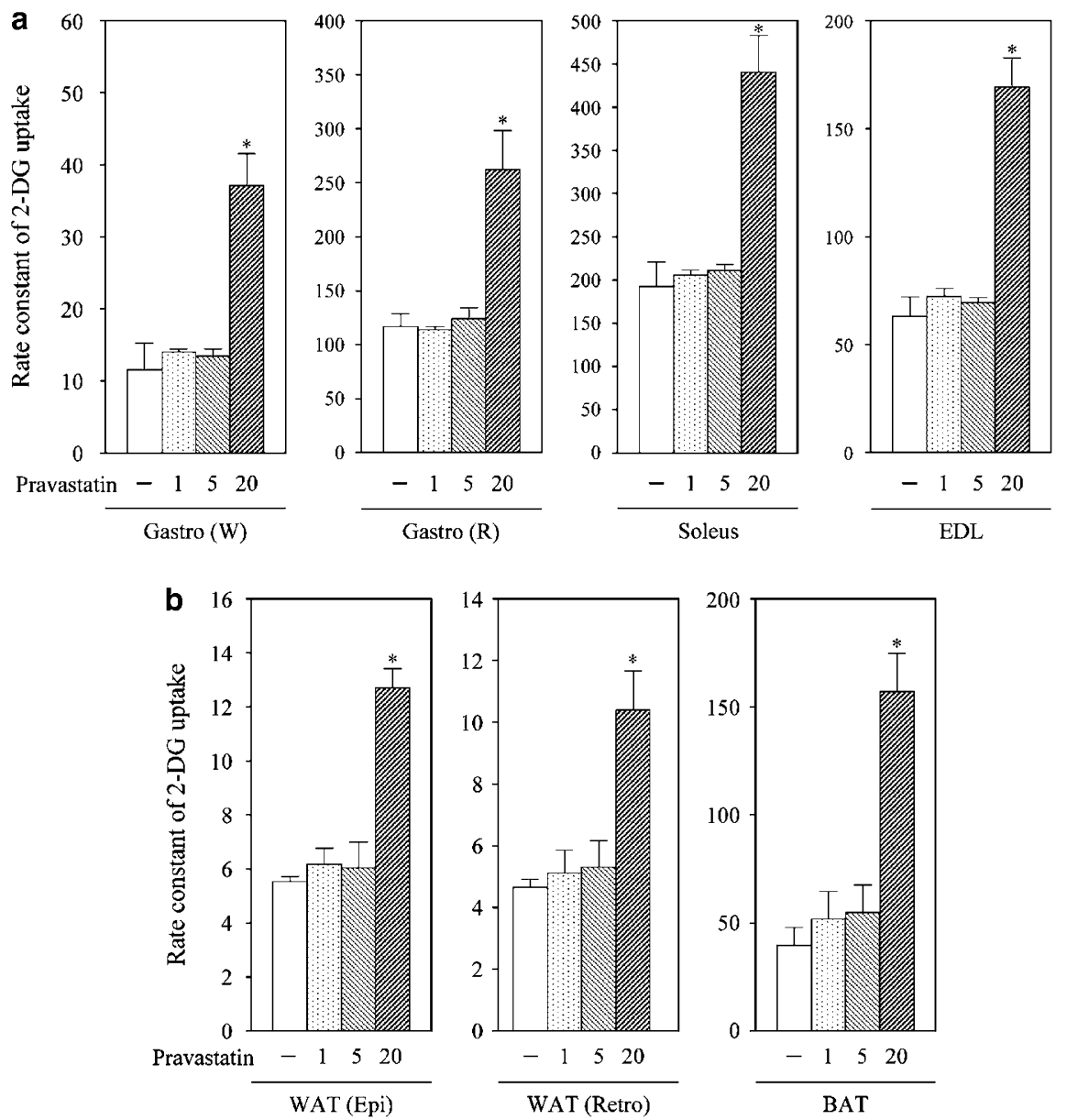

Figure 4 Effect of pravastatin on tissue glucose uptake. KK-Ay mice were treated with pravastatin at the doses indicated. Tissue glucose uptake was measured using 2-[ $\left[{ }^{3} \mathrm{H}\right]$ deoxy-D-glucose (2-DG) as described in 'Methods'. Data are mean \pm s.e.m. from 6 to 8 animals for each group. (a) Gastro (W): white part of gastrocnemius muscle, Gastro (R): red part of gastrocnemius muscle, Soleus: soleus muscle, EDL: extensor digitorum longus muscle. (b) WAT (Epi): epididymal white adipose tissue, WAT (Retro): retroperitoneal white adipose tissue, BAT: interscapular brown adipose tissue. Pravastatin: $\mathrm{mg} \mathrm{kg}^{-1}$ day $^{-1}$. $* P<0.05$ vs. control.

On the other hand, statins are widely used for patients with hypercholesterolemia, with the expectation of protective effects on vasculature. Indeed, recent accumulating studies indicate that statins can exert pleiotropic effects on cardiovascular diseases. However, the effect of statins on glucose intolerance is still controversial. A statin retarded the progression of glucose intolerance in a type II diabetic model, the Otsuka Long-Evans Tokushima Fatty (OLETF) rat. ${ }^{15}$ On the other hand, Satoh et al. ${ }^{16}$ reported that a statin did not improve glucose intolerance in another diabetes model, the Goto-Kakizaki rat.

This study indicated that pravastatin improved OGTT and increased tissue glucose uptake in type II diabetic KK- $\mathrm{A}^{\mathrm{y}}$ mice in a dose-dependent manner. These effects were apparent at a dose of $20 \mathrm{mg} \mathrm{kg}^{-1} \mathrm{day}^{-1}$, which decreased plasma cholesterol (Table 1, Figure 2). These results suggest the possibility that pravastatin can improve glucose intolerance through a modification of cholesterol metabolism and/or independent of HMG-CoA reductase inhibition. Our results were similar to those using OLETF rats, but different from those using Goto-Kakizaki rats. Such differences are probably due to differences in the strain of animals and type and dose of statins.

In addition, a noneffective dose of pravastatin could improve OGTT and increase tissue glucose uptake in combination with a noneffective dose of an ARB, olmesartan (Figure 5). We have previously reported that ARBs, including olmesartan, improve OGTT by increasing glucose uptake into skeletal muscle. ${ }^{4,14}$ Interestingly, the results of this study suggest that the combination of pravastatin and olmesartan synergistically enhances their effects on glucose intolerance in diabetic mice.

Such synergistic actions were observed in the effects of a RAS blocker and a calcium channel blocker on cardiovascular remodeling or on ischemic brain damage. ${ }^{5,17-19}$ On the other hand, it is reported that statins have pleiotropic effects on cardiovascular disease. We have reported that fluvastatin attenuated atherosclerosis formation synergistically with an ARB, valsartan, because of the inhibition of oxidative stress in the vasculature. ${ }^{8}$ Statins also reduce vascular remodeling. ${ }^{8,20,21}$ However, this study suggests that statins also enhance the improvement of glucose intolerance in type II diabetes caused by ARBs.

The mechanism of action of this combination on glucose intolerance remains unclear. In this study, pravastatin and/or a combination of noneffective doses of pravastatin and olmesartan did not modify the plasma insulin level. Thus, these drugs may not affect insulin secretion. Instead, this combination increased glucose uptake into skeletal muscle and adipose tissue (Figure 5). These results suggest that the combination of pravastatin and olmesartan increased insulin sensitivity in insulin-sensitive tissues. 

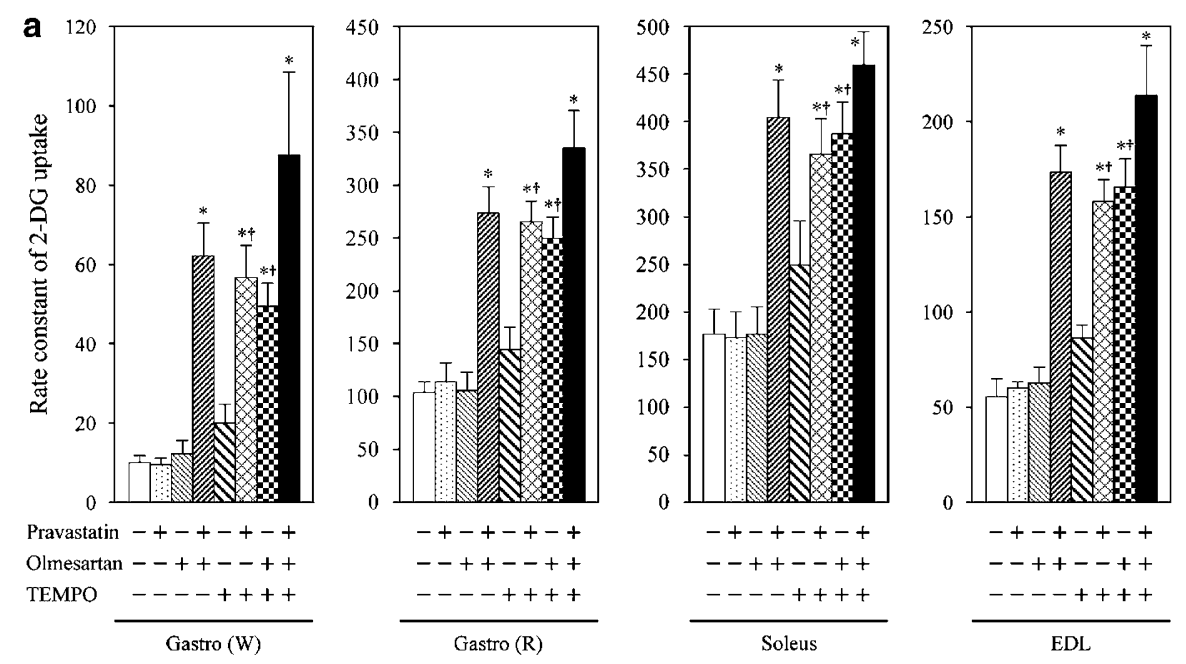
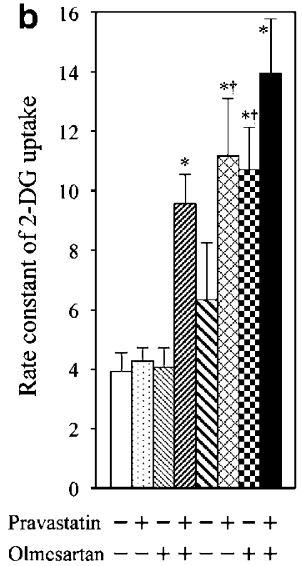

TEMPO ----++++

WAT (Epi)
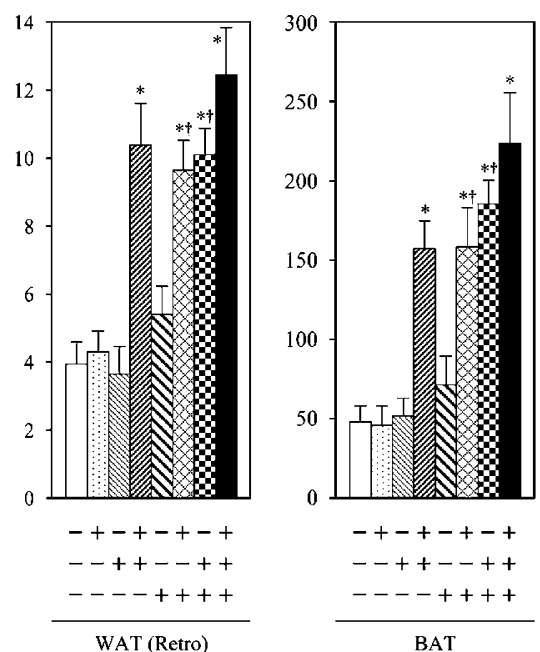

Figure 5 Effect of pravastatin and olmesartan on tissue glucose uptake and involvement of oxidative stress. KK-Ay mice were treated with the lower dose of pravastatin $\left(1.0 \mathrm{mg} \mathrm{kg}^{-1} \mathrm{day}^{-1}\right)$, olmesartan $\left(0.5 \mathrm{mg} \mathrm{kg}^{-1} \mathrm{day}^{-1}\right)$ and/or tempol, and tissue glucose uptake was measured using 2-[ $\left.{ }^{3} \mathrm{H}\right] \mathrm{deoxy}-\mathrm{D}-\mathrm{glucose}(2-\mathrm{DG})$ as described in 'Methods'. Data are mean \pm s.e.m. from 5 to 6 animals for each group. (a) Gastro (W): white part of gastrocnemius muscle, Gastro (R): red part of gastrocnemius muscle, Soleus: soleus muscle, EDL: extensor digitorum longus muscle. (b) WAT (Epi): epididymal white adipose tissue, WAT (Retro): retroperitoneal white adipose tissue, BAT: interscapular brown adipose tissue. TEMPO: tempol. ${ }^{*} P<0.05$ vs. control, ${ }^{\dagger} P<0.05$ vs. pravastatin or olmesartan without tempol.

Previous reports indicate that oxidative stress induces insulin resistance. $^{22-26}$ We have previously reported that superoxide production was decreased by an ARB in the skeletal muscle of KK-Ay mice. ${ }^{4}$ Other papers indicate that antihypertensive drugs attenuate superoxide production. ${ }^{27-29}$ In this study, an antioxidant, tempol, enhanced the effect of pravastatin or olmesartan (Figure 5). In Figure 5, tempol increased the tissue glucose uptake caused by pravastatin or olmesartan. These results suggest that a synergistic effect of a combination of pravastatin and olmesartan on glucose intolerance was induced at least in part through the attenuation of oxidative stress.

Oxidative stress induces vascular endothelial dysfunction and inflammation, and thereby may impair arterial function and blood flow. ${ }^{30,31}$ As statins attenuate oxidative stress and inflammation, it may be possible that statins improve tissue microcirculation. Such an improvement of microcirculation might be involved in the beneficial effects of the combination of pravastatin and olmesartan on glucose intolerance.
Moreover, it is reported that pravastatin suppressed TNF- $\alpha$-induced intracellular oxidants in cultured cardiomyocytes and improved glucose uptake. ${ }^{31}$ We previously observed that treatment with an ARB decreased the expression of TNF- $\alpha$ in the skeletal muscle ${ }^{4,32}$ and the plasma FFA level (unpublished data) in diabetic mice. As inflammatory factors, such as TNF- $\alpha$, and FFA, are involved in insulin resistance, the effect of a combination of a statin and an ARB may be mediated by a suppression of TNF- $\alpha$ and/or FFA, which should be further investigated.

Taken together, although a statin or an ARB can attenuate glucose intolerance in diabetic mice, the combination of a statin and an ARB synergistically improves glucose intolerance by an increase in insulin sensitivity in skeletal muscle and adipose tissue. These beneficial actions of the combination seem to be induced, at least partly, by the inhibition of oxidative stress in insulin-sensitive tissues. We can expect that a combination of a statin and an ARB could provide future new therapeutic strategies in terms of an 
improvement of the metabolic syndrome, resulting in a decrease in cardiovascular events.

\section{CONFLICT OF INTEREST}

The authors declare no conflict of interest.

\section{ACKNOWLEDGEMENTS}

This work was supported by a Grant-in-Aid for Scientific Research from the Ministry of Education, Science, Sports and Culture of Japan.

1 Cooper SA, Whaley-Connell A, Habibi J, Wei Y, Lastra G, Manrique C, Stas S, Sowers JR Renin-angiotensin-aldosterone system and oxidative stress in cardiovascular insulin resistance. Am J Physiol Heart Circ Physiol 2007; 293: H2O09-H2O23.

2 Engeli S. Role of the renin-angiotensin-aldosterone system in the metabolic syndrome. Contrib Nephrol 2006; 151: 122-134.

3 Chu KY, Lau T, Carlsson PO, Leung PS. Angiotensin II type 1 receptor blockade improves beta-cell function and glucose tolerance in a mouse model of type 2 diabetes. Diabetes 2006; 55: 367-374.

4 Shiuchi T, Iwai M, Li HS, Wu L, Min LJ, Li JM, Okumura M, Cui TX, Horiuchi M. Angiotensin II type-1 receptor blocker valsartan enhances insulin sensitivity in skeletal muscles of diabetic mice. Hypertension 2004; 43: 1003-1010.

5 Iwai $\mathrm{M}$, Chen $\mathrm{R}$, Ide A, Iwanami J, Tomochika H, Tomono Y, Mogi M, Horiuchi M. The calcium-channel blocker, azelnidipine, enhances the inhibitory action of $\mathrm{AT}_{1}$ receptor blockade on ischemic brain damage. J Hypertens 2006; 24: 2023-2031.

6 Jasiñska M, Owczarek J, Orszulak-Michalak D. Statins: a new insight into their mechanisms of action and consequent pleiotropic effects. Pharmacol Rep 2007; 59: 483-499.

7 Castro PF, Miranda R, Verdejo HE, Greig D, Gabrielli LA, Alcaino H, Chiong M, Bustos C, Garcia L, Mellado R, Vukasovic JL, Godoy I, Lavandero S. Pleiotropic effects of atorvastatin in heart failure: role in oxidative stress, inflammation, endothelial function, and exercise capacity. J Heart Lung Transplant 2008; 27: 435-441.

8 Horiuchi M, Cui TX, Li Z, Li JM, Nakagami H, Iwai M. Fluvastatin enhances the inhibitory effects of a selective angiotensin II type 1 receptor blocker, valsartan, on vascular neointimal formation. Circulation 2003; 107: 106-112.

9 Cholesterol Treatment Trialists' (CTT) Collaborators Kearney PM, Blackwell L, Collins R, Keech A, Simes J, Peto R, Armitage J, Baigent C. Efficacy of cholesterollowering therapy in 18,686 people with diabetes in 14 randomised trials of statins: a meta-analysis. Lancet 2008; 371: 117-125.

10 Neil HA, DeMicco DA, Luo D, Betteridge DJ, Colhoun HM, Durrington PN, Livingstone SJ, Fuller JH, Hitman GA, CARDS Study Investigators. Analysis of efficacy and safety in patients aged 65-75 years at randomization: Collaborative Atorvastatin Diabetes Study (CARDS). Diabetes Care 2006; 29: 2378-2384.

11 Suto J, Matsuura S, Imamura K, Yamanaka H, Sekikawa K. Genetic analysis of noninsulin-dependent diabetes mellitus in KK and KK-Ay mice. Eur J Endocrinol 1998; 139: 654-661.

12 Sudo M, Minokoshi Y, Shimazu T. Ventromedial hypothalamus stimulation enhances peripheral glucose uptake in anesthetized rats. Am J Physiol 1991; 261: E298-E303.

13 Vallerand AL, Pérusse F, Bukowiecki LJ. Cold exposure potentiates the effect of insulin on in vivo glucose uptake. Am J Physiol 1987; 253: E179-E186.

14 Iwai M, Li HS, Chen R, Shiuchi T, Wu L, Min LJ, Li JM, Tsuda M, Suzuki J, Tomono Y, Tomochika H, Mogi M, Horiuchi M. Calcium channel blocker azelnidipine reduces glucose intolerance in diabetic mice via different mechanism than angiotensin receptor blocker olmesartan. J Pharmacol Exp Ther 2006; 319: 1081-1087.
15 Yu Y, Ohmori K, Chen Y, Sato C, Kiyomoto H, Shinomiya K, Takeuchi H, Mizushige K, Kohno M. Effects of pravastatin on progression of glucose intolerance and cardiovascular remodeling in a type II diabetes model. J Am Coll Cardiol 2004; 44: 904-913.

16 Satoh K, Keimatsu N, Kanda M, Kasai T, Takaguri A, Sun F, Ichihara K. HMG-CoA reductase inhibitors do not improve glucose intolerance in spontaneously diabetic GotoKakizaki rats. Biol Pharm Bull 2005; 28: 2092-2095.

17 Bakris GL. Combined therapy with a calcium channel blocker and an angiotensin II type 1 receptor blocker. J Clin Hypertens (Greenwich) 2008; 10(Suppl 1): 27-32.

18 Nesbitt SD. Antihypertensive combination therapy: optimizing blood pressure control and cardiovascular risk reduction. J Clin Hypertens (Greenwich) 2007; 9(Suppl 4): 26 32

19 Suzuki J, Iwai M, Li Z, Li JM, Min LJ, Ide A, Yoshii T, Oshita A, Mogi M, Horiuchi M. Effect of combination of calcium antagonist, azelnidipine, and $\mathrm{AT}_{1}$ receptor blocker, olmesartan, on atherosclerosis in apolipoprotein E-deficient mice. J Hypertens 2005; 23: 1383-1389.

20 Penumathsa SV, Thirunavukkarasu M, Koneru S, Juhasz B, Zhan L, Pant R, Menon VP, Otani $\mathrm{H}$, Maulik N. Statin and resveratrol in combination induces cardioprotection against myocardial infarction in hypercholesterolemic rat. J Mol Cell Cardiol 2007; 42: 508-516.

21 Yamamoto E, Yamashita T, Tanaka T, Kataoka K, Tokutomi Y, Lai ZF, Dong YF, Matsuba $\mathrm{S}$, Ogawa H, Kim-Mitsuyama S. Pravastatin enhances beneficial effects of olmesartan on vascular injury of salt-sensitive hypertensive rats, via pleiotropic effects. Arterioscler Thromb Vasc Biol 2007; 27: 556-563.

22 Wei Y, Chen K, Whaley-Connell AT, Stump CS, Ibdah JA, Sowers JR. Skeletal muscle insulin resistance: role of inflammatory cytokines and reactive oxygen species. $A m \mathrm{~J}$ Physiol Regul Integr Comp Physiol 2008; 294: R673-R680.

23 Bonnard C, Durand A, Peyrol S, Chanseaume E, Chauvin MA, Morio B, Vidal H, Rieusset J. Mitochondrial dysfunction results from oxidative stress in the skeletal muscle of diet-induced insulin-resistant mice. J Clin Invest 2008; 118: 789-800.

24 Henriksen EJ. Improvement of insulin sensitivity by antagonism of the renin-angiotensin system. Am J Physiol Regul Integr Comp Physiol 2007; 293: R974-R980.

25 Maddux BA, See W, Lawrence Jr JC, Goldfine AL, Goldfine ID, Evans JL. Protection against oxidative stress-induced insulin resistance in rat $\mathrm{L} 6$ muscle cells by mircomolar concentrations of alpha-lipoic acid. Diabetes 2001; 50: 404-410.

26 Smith SR, Bai F, Charbonneau C, Janderová L, Argyropoulos G. A promoter genotype and oxidative stress potentially link resistin to human insulin resistance. Diabetes 2003; 52: 1611-1618.

27 Sicard P, Delemasure S, Korandji C, Grand AS, Lauzier B, Guilland JC, Duvillard L, Zeller M, Cottin Y, Vergely C, Rochette L. Anti-hypertensive effects of rosuvastatin are associated with decreased inflammation and oxidative stress markers in hypertensive rats. Free Radic Res 2008; 42: 226-236.

28 Ohmura C, Watada H, Shimizu T, Sakai K, Uchino H, Fujitani Y, Kanazawa A, Hirose T, Kawamori R. Calcium channel blocker, azelnidipine, reduces lipid hydroperoxides in patients with type 2 diabetes independent of blood pressure. Endocr J 2007; 54: 805-811.

29 Matsubara M, Akizuki O, Ikeda J, Saeki K, Yao K, Sasaki K. Benidipine, an antihypertensive drug, inhibits reactive oxygen species production in polymorphonuclear leukocytes and oxidative stress in salt-loaded stroke-prone spontaneously hypertensive rats. Eur J Pharmacol 2008; 580: 201-213.

30 Hartge MM, Unger T, Kintscher U. The endothelium and vascular inflammation in diabetes. Diab Vasc Dis Res 2007; 4: 84-88.

31 Ding $\mathrm{H}$, Triggle CR. Endothelial cell dysfunction and the vascular complications associated with type 2 diabetes: assessing the health of the endothelium. Vasc Health Risk Manag 2005; 1: 55-71.

32 Iwai M, Chen R, Imura Y, Horiuchi M. TAK-536, a new AT1 receptor blocker, improves glucose intolerance and adipocyte differentiation. Am J Hypertens 2007; 20: $579-586$ 